\title{
La Corte Penal Internacional inaugura un nuevo tipo de relaciones en la comunidad de naciones
}

\section{IVO GARCÍA VARGAS*}

\section{RESUMEN}

Los estados que adoptaron el Estatuto de Roma expresaron con claridad su decisión de luchar contra la impunidad de crímenes contra la humanidad (genocidio, crímenes de guerra, crímenes de lesa humanidad y agresión); La creación de la Corte Penal Internacional (máximo organismo de administración de justicia para sancionar y castigar la violación de los DDHH y el DIH) significa el resultado del trabajo mancomunado de la comunidad de naciones y de su consenso respecto a que su acción y cobertura deberá garantizar la protección integral de los derechos humanos, desde el núcleo del derecho consuetudinario mínimo hasta la preservación de la paz orbital, juzgando y castigando individualmente todo tipo de crímenes contra la humanidad violatorios del Derecho Internacional Humanitario. El carácter integral, autónomo e independiente de la Corte Penal Internacional avisora en su intencionalidad política que la aplicación de justicia no se hará como en el pasado, en donde la conformación de tribunales y sus respectivos códigos representaban intereses específicos de hegemonías internacionales, relaciones de poder predeterminadas y negociaciones de roles individualistas que representaron inmunidades perversas, arrojando el cuadro de impunidad más atroz jamás presentado.

\section{PALABRAS CLAVE}

Permanente, Autónoma, Universal, Castigar.

\footnotetext{
Asesor del Centro de Estudios de Economía y Humanismo Louis Joseph Lebret (Universidad Santo Tomás); Secretario Académico del Programa Técnico Auxiliar de la Justicia de la Fundación San francisco de Asís; docente de la Fundación ya mencionada, de la Universidad Santo Tomás y de la Universidad la Gran Colombia; Abogado egresado de la Facultad de Derecho y Ciencias Políticas de la Universidad Santo Tomás (Bogotá); especializado en Estudios del Desarrollo Internacional, Gestión de Proyectos, Estudios de Francés Moderno, Civilización Francesa e Instituciones Suizas en la Universidad de Ginebra (Suiza). Ex Director General de Asuntos Indígenas del Ministerio del Interior (Colombia). Profesor invitado de la Universidad de Verano de Derechos Humanos y del Derecho a la Educación organizada por la Universidad de Ginebra, las Naciones Unidas, la OIDEL y el SUM (Ginebra, Suiza).
} 


\section{ABSTRACT}

The States accepted the Rome Statute clearly expressed their decision to fight against the impunity of the crimes againts humanity (genocide, war crimes, crime of lese-humanity and aggression); The creation of the international Criminal Court (the highest judicial organization in charge of punishing Humanitarian Law and Human Rights violations) means the result of the joint work of community nations and reflects their assent in regards that its action and coverage will guarantee human rights full protection, starting from the nucleus of the minimal common law, to world peace preservation, judging and punishing all Kinds of crimes against humanitarian law. The characteristics of the International Criminal Court (integrity, autonomy and independence) show its political intention, that justice application will not be like in the past, where tribunal's conformation and their codes, represented specific interests of international hegemonies, predetermined power relations and individualist negotiations that represented perverse immunities; which resulted in the most atrocious picture of impunity ever seen.

\section{KEY WORDS}

Permanent, Autonomous, Universal, To Punish

\section{ANTECEDENTES 1}

El intento de creación de un mecanismo de jurisdicción penal internacional no tiene una connotación reciente. Ya en las postrimerías de la Primera Guerra Mundial aparecieron propuestas pugnando por la constitución de un Tribunal Criminal Internacional. En 1919, el Tratado de Versalles planteó la necesidad de crear un instrumento de esta naturaleza para juzgar al Káiser Alemán Guillermo II y a oficiales Turcos y Alemanes acusados de ser criminales de guerra.

Aún cuando ese instrumento no se creó en ese momento, debido a las condiciones de correlación y disputa por la hegemonía entre las potencias mundiales, este cometido se mantuvo hasta la Convención para la Creación de la Corte Penal Internacional realizada en 1937, en la cual fue adoptado el tratado para su establecimiento, pero no logró entrar en vigor debido a que fue escaso el número de estados que lo ratificaron.
Los intentos de la creación del mecanismo internacional de juzgamiento se empezó a cristalizar mediante el acuerdo para el castigo de los criminales de guerra del eje Europeo, luego del desenlace de la Segunda Guerra Mundial. Tal acuerdo se firmó el 8 de agosto de 1945: ley No 10 del Consejo de Control Aliado en Alemania.

Simultáneamente se dio la Proclama Especial del Comandante Supremo de las Potencias Aliadas para el establecimiento de un Tribunal Militar Internacional para el Lejano Oriente, la cual fue adoptada en Tokio el 19 de enero de 1946.

Estos dos instrumentos se impulsaron con el objetivo de procesar y juzgar a los dirigentes Alemanes y Japoneses incursos en crímenes de guerra* contra la humanidad en el desarrollo de la Segunda Guerra Mundial.

1 PIGRAU, Sole Antoni. Revista Naciones Unidas, junio de 1998.

* Crímenes de guerra: son los delitos graves cometidos contra las personas o bienes protegidos por el Derecho Internacional Humanitario (DIH). 
No obstante que los Tribunales de Nüremberg y Tokio fueron precedentes importantes en el avance para castigar la impunidad internacional, éstos se caracterizaron por ser meramente coyunturales y focalizados a dirimir unilateralmente la criminalidad que significó la Segunda Guerra Mundial.

El significado y resultados de los dos mencionados tribunales conllevó a que en 1948 las Naciones Unidas adoptaran la Convención para la Prevención y Sanción del Delito de Genocidio, la cual enfatizó en la necesidad de la creación de una Corte Penal Internacional.

El Código de crímenes contra la paz y la seguridad de la humanidad se elaboró por la Comisión de Derecho Internacional, siendo presentado ante la Asamblea General de las Naciones Unidas en 1951 y 1954 . Este no fue adoptado por presentarse el vacío de un consenso sobre la definición del crimen de Agresión.

Sólo hasta la Asamblea General de las Naciones Unidas de 1974 se precisó una definición consensuada sobre la Agresión, a través de la Resolución $\mathrm{N}^{\circ} 3314$ del 14 de septiembre de ese mismo año ${ }^{2}$.

Todos los intentos que se dieron para crear la Corte Penal Internacional desde la década de 1950 hasta la década de 1990 se truncaron, principalmente por las tensiones y dificultades de la Guerra Fría ${ }^{3}$.

En la coyuntura de 1992, el exterminio étnico presentado en la recién disuelta Yugoslavia y en Ruanda, obligó a las Naciones Unidas a dar una respuesta contundente a las acciones de crímenes contra la humanidad que se cometieron contra estos pueblos.
Por ello, se puede afirmar que el intento de mayor significación y alcance de aplicación fáctica eficaz se desarrolló a partir de la década de 1990. El Consejo de Seguridad de las Naciones Unidas creó el Tribunal Penal Internacional para la recién disuelta Yugoslavia a través de la Resolución 808 del 22 de febrero de 1993, siendo adoptado su Estatuto a través de la Resolución 827 del 25 de mayo de 1993. Atendiendo análogos requerimientos de juzgamiento por crímenes de guerra, el Consejo de Seguridad creó el Tribunal Penal Internacional para Ruanda a través de la resolución 955 del 8 de noviembre de $1994^{4}$.

Estos dos tribunales, además de haber cumplido una labor de máxima importancia en la atención a la impunidad que se estaba presentando en los mencionados conflictos, mantuvieron su vigencia en el tiempo, en sus alcances y repercusiones, sobre todo en lo tocante al propósito de la creación de la Corte Penal Internacional.

No obstante, la debilidad política y jurídica de dichos tribunales estribó en que se constituyeron para juzgar crímenes ya cometidos, con su consecuente carácter de ámbitos jurisdiccionales ad hoc, siendo por lo tanto limitados por su competencia restringida a conflictos específicos, sin la posibilidad de tener jurisdicción para atender coberturas geográficas mayores sobre otros crímenes cometidos en otras latitudes.

Este avance fue estratégico si se tiene en cuenta que hasta ese momento, los intereses y la conveniencia política que habían impuesto las potencias mundiales para los otros Estados, y entre éstas mismas, no habían posibilitado suceptibilizar condiciones objetivas que permitieran dar paso a un instrumento único y permanente de aplicación de justicia con cobertura internacional.

\footnotetext{
CORTE CONSTITUCIONAL. Sentencia N ${ }^{\circ}$ C-578, julio 30 de 2002.

Ibídem

MENDOZA, Álvaro. La Corte Penal Internacional y la impunidad. Universidad Militar Nueva Granada. Bogotá, noviembre de 2001.
} 


\section{LA CREACIÓN DE LA CORTE PENAL INTER- NACIONAL}

El concierto de las relaciones interestatales a nivel mundial siempre se caracterizó por las dinámicas de poder hegemónico visadas de contradicciones irreconciliables indistintamente en los planos políticos, económicos, religiosos, ideológicos y culturales. Por ello, concurrir a un acuerdo de creación de la Corte Penal Internacional era hasta hace poco tiempo una posibilidad muy lejana y esquiva.

Sin embargo, en el ámbito internacional se fueron argumentando condiciones políticas que fueron urgiendo la necesidad de la constitución de tal acuerdo. No fue precisamente por las relaciones armónicas político-jurídicas de los Estados por lo que se encaminó y fortaleció tal iniciativa.

Es imprescindible reseñar que fue el enfoque integral y la acción de las organizaciones internacionales y de las Organizaciones No Gubernamentales las que suscitaron intencionalidad positiva, argumentos de soporte y contenidos de alcance orbital de conveniencia universal. Este elemento fue vital para que se llegara a la concreción de la creación de la Corte Penal Internacional ${ }^{6}$.

Desde luego, el proceso de adopción de un acuerdo básico de contenidos estuvo problematizado por asuntos que se discutieron en la ONU desde 1948. Por ello, en intervalos de períodos recientes los organismos responsabilizados de tareas en torno al Estatuto tuvieron que tratar controversias profundas de contenidos estratégicos tanto para los Estados Tratantes como para la conveniencia de la comunidad internacional.

Esta complejidad controversial en candentes temas fue tramitada por: la Comisión Legal Internacional, autor del Estatuto Preliminar, en el período 1990-1994; por la Asamblea General de las Naciones Unidas en 1995; por el Comité Preparatorio del Estatuto en el período 1996-1998; y por la Conferencia de Plenipotenciarios de las Naciones Unidas entre Junio-Julio de $1998^{7}$.

En este discernimiento de intereses y enfoques, el factor de mayor complejidad lo constituyó todo lo relacionado con los alcances de la competencia de la Corte Penal Internacional. Entre los aspectos más polémicos, se podrían reseñar los siguientes:

En primera instancia, los que tienen que ver con el catálogo de crímenes con los cuales tendría competencia la Corte Penal Internacional. Al final del acuerdo fueron excluidos los que tienen que ver con la intervención, la dominación colonial y extranjera, el terrorismo internacional, el tráfico ilícito de estupefacientes, los daños intencionales y graves al medio ambiente, los crímenes contra las Naciones Unidas y su personal conexo. En el Estatuto quedaron tipificados los delitos referidos al genocidio, los crímenes de guerra, los crímenes de lesa humanidad y la agresión.

En segunda instancia, se discutía lo referente a la legitimidad de la imputación de un asunto para acceder a su sometimiento a la Corte. Un enfoque argumentaba que esta competencia la

5 PIGRAU Sole, Antoni. Revista Naciones Unidas, junio de 1998.

6 PETER, Maina Chris. Revista Cruz Roja Internacional, julio 15 de 2002.

7 CORTE CONSTITUCIONAL. Sentencia N C-578, julio 30 de 2002. 
deberían tener meramente los Estados y el Consejo de Seguridad de las Naciones Unidas. Otra postura propugnó fuertemente porque ello debería ser definido principalmente por el Fiscal de la Corte Penal Internacional con plena autonomía y desde sus propias consideraciones e investigaciones, lo cual garantizaría imparcialidad jurídica y política.

En tercera instancia, la discusión se situó en lo referente a la competencia automática e inmediata de la Corte sobre el juzgamiento de los crímenes, en relación a la independencia del demandante. La diferencia estribaba en el carácter y mecanismo del consentimiento respectivo de Ios Estados para que la Corte asumiera la competencia del juzgamiento del delito.

En cuarta instancia, la discusión se detuvo reiteradamente en el punto sobre las causas de inadmisibilidad de un delito por parte de la Corte, siendo este aspecto de notoria controversia. Entre estas causas, se reseñaban como las más protuberantes las que tienen que ver con los casos en los cuales los Estados ya habrían investigado y decidido no incoar acción penal; o en Ios casos en los cuales los Estados ya han asumido el objeto de instrucción por estar dentro de su jurisdicción; o en los casos en los cuales la Corte consideraría no tendrían gravedad suficiente para ser asumidos como delitos internacionales.

En quinta instancia, siendo tal vez uno de los aspectos más controvertidos, fue el relacionado con los roles, dinámicas y competencias del Consejo de Seguridad de las Naciones Unidas y la Corte Penal Internacional. Se trataba de establecer jerarquías, mecanismos de supeditación, métodos de trabajo y procedimientos regulatorios, que no fueran suceptibles de entorpecer las respectivas competencias entre los dos organismos ${ }^{8}$.

Finalmente, las diferencias existentes en estos aspectos fueron tramitadas adecuadamente con los instrumentos y los organismos que la ONU habilitó para tal efecto, con el aporte oportuno de los Estados participantes, lo cual conllevó la concreción del Estatuto aprobado en Roma en 1998.

En este arduo proceso es imprescindible significar la gestión simultánea, prospectiva, incidente y eficaz de las Organizaciones Intergubernamentales y las Organizaciones No Gubernamentales, en particular Amnistía Internacional, la Comisión No Gubernamental por una Corte Penal Internacional y la Comisión Internacional de Juristas ${ }^{9}$.

Luego de variadas polémicas sobre el mecanismo de puesta en común de la propuesta de Estatuto y de la conformación de la Corte, la $52^{\circ}$ Sesión de la Asamblea General de la ONU convocó la Conferencia de Plenipotenciarios de las Naciones Unidas, la cual tuvo como único objetivo definir sobre su conveniencia internacional y la viabilidad de su implementación.

En la Conferencia de Plenipotenciarios de las Naciones Unidas, el Estatuto de Roma de la Corte Penal Internacional fue aprobado el 17 de julio de 1998, con 120 votos a favor, 7 en contra y 21 abstenciones. Se abrió a la firma siendo ratificado por el sexagésimo Estado el 11 de abril de 2002, entrando en vigor el 1 de julio de 2002.

\footnotetext{
8 Ibídem.

9 Ibídem.
} 


\section{LA CORTE PENAL INTERNACIONAL Y LAS CONSTITUCIONES NACIONALES ${ }^{10}$}

Luego de aprobado el Estatuto de Roma de la Corte Penal Internacional en 1998, en el marco del proceso de su ratificación, se abrió un profuso debate en todos los países en torno a los niveles de compatibilidad entre éste y las Constituciones Políticas de los Estados Nacionales.

Fueron variadas las polémicas sobre temas indistintos que no habrían podido tener concordancia con la Constituciones Nacionales, pero fueron tres de éstos los que se reiteraron en casi todos los casos. Estos tuvieron que ver con la extradición, las inmunidades y la cadena perpetua.

La discusión sobre las incompatibilidades fueron zanjadas por algunos Estados a través de enmiendas a sus Constituciones como Francia, Bélgica y actualmente se está debatiendo esta posibilidad en Brasil. Otros Estados asumieron el enfoque interpretativo, el cual garantiza la elevación de una lectura armoniosa entre el Estatuto de la Corte y las Constituciones, pues ésta se argumenta desde el principio de la complementariedad en cada caso particular.

En el caso de la extradición, las tensiones se debilitan por posibles interpretaciones unilaterales, pues el Estatuto de Roma es claro al hacer la distinción entre extradición y la entrega de una persona por un Estado Nacional a la Corte Penal Internacional. La extradición se define específicamente como la entrega de una persona por un Estado a otro Estado. La entrega de una persona a la Corte es ante todo un ejercicio de cooperación entre un Estado y la instancia internacional de justicia que representa a la Asamblea de los Estados partes de todo el mundo.
Además, en los casos en los cuales la Constituciones no permiten la salida de sus ciudadanos, se aplicaría el principio de la complementariedad, la cual obliga a los Estados a llevar a cabo las investigaciones y la aplicación de justicia. Este principio es mucho más aplicable en el caso de los Estados que ya en el pasado han adherido tratados internacionales en los cuales se han comprometido a juzgar y a extraditar a personas incursas en crímenes como la tortura, la violación de los Convenios de Ginebra y el genocidio.

En el caso de las inmunidades, el análisis se centró en la posible rigidez definida en el Estatuto de Roma respecto al tema. El Estatuto es claro al establecer que se aplicará justicia por igual a todos sin distinción de cargos oficiales o de otra índole; por lo tanto quedan incluidas todas las personas que, aún teniendo inmunidad del derecho interno, serán procesados y juzgados por la Corte. Esto incluye a los jefes de Estado o de Gobierno.

En las argumentaciones sobre las posibles incompatibilidades en el tema de las inmunidades, el análisis integral enfatiza que ninguna Constitución de ninguna parte del mundo instituye la inmunidad como figura jurídica para amparar la impunidad sobre crímenes que están instituidos en el Estatuto de Roma. Por el contrario, la figura de la inmunidad en las Constituciones de los Estados se dirigen a viabilizar versatilidad y claridad de las funciones públicas.

En los casos en los cuales se ha alegado incompatibilidad rotunda, se prevee también la aplicación del principio de la complementariedad, pues al igual que en el tema de la extradición, muchos Estados han firmado en el pasado tratados internacionales en los cuales se han comprometido a enjuiciar o extraditar a una persona sin tener en cuenta el cargo oficial o inmunidad del acusado. 
Respecto a la cadena perpetua, la incompatibilidad conceptual es clara entre lo definido en el Estatuto de Roma y Constituciones de algunos países que prohiben la reclusión a perpetuidad. La prisión a perpetuidad definida por el Estatuto, se especifica para los casos en los cuales se justifique la extrema gravedad del crimen y las circunstancias personales del condenado.

Además de lo anterior, el Estatuto también prevee la revisión de la pena una vez hayan transcurridos 25 años de prisión, para analizar si ésta se puede reducir.

En este caso, el Estatuto de Roma en el artículo 80 es claro al determinar que nada de lo dispuesto se entenderá en perjuicio de la aplicación por los Estados de las penas prescritas o prohibidas por las legislaciones del derecho interno. Es más, ningún Estado está obligado a aplicar la cadena perpetua definida por la Corte.

Esto es compatible con el principio de la complementariedad, pues en este caso el acusado sería juzgado y penalizado por las legislaciones internas, lo cual garantiza que no habrá impunidad.

\section{CARÁCTER, NATURALEZA Y COBERTURA DE LA CORTE PENAL INTERNACIONAL ${ }^{11}$}

La Corte Penal Internacional, de carácter permanente e independiente, es el máximo organismo de administración de justicia para sancionar y castigar la violación de los derechos humanos inherentes a atentar contra la integridad de la humanidad y la preservación de la paz mundial.

Por lo tanto investigará, procesará y enjuiciará a los individuos acusados de infringir delitos contra el Derecho Internacional Humanitario que por alguna razón no hayan podido ser juzgados en sus respectivos países. Estos delitos son:

Genocidio: Es la matanza o lesión grave a los miembros de un grupo con intención de destruirlo total o parcialmente. También se comete genocidio cuando se establecen medidas para impedir el nacimiento de personas del grupo o cuando los niños son trasladados por la fuerza a otros grupos.

Crímenes de guerra: son los delitos graves cometidos contra las personas o bienes protegidos por el Derecho Internacional Humanitario (D.I.H.).

Crímenes de lesa humanidad: Son aquellos que se cometen como parte de un ataque generalizado o sistemático contra la población civil. Entre ellos se destacan: el asesinato, el exterminio, la esclavitud, la deportación o desplazamiento forzoso, el encarcelamiento o privación de la libertad física en violación de normas fundamentales del derecho internacional, la tortura, la violación, la esclavitud sexual, la prostitución forzada.

Agresión: Son aquellos que un Estado comete contra otro. No se ha reglamentado ni especificado esta clase de delito.

Su ámbito jurisdiccional no está limitado ni en tiempo ni ubicación geopolítica, siendo aplicable de manera no retroactiva en los ámbitos territoriales de los Estados que la adhieran.

Su relación jurisdiccional y su respectiva aplicación de justicia en relación con los Estados, se basará en los principios de la complementariedad y subsidiaridad, siendo de éstos la responsabilidad inicial y primordial para la aplicación de la justicia y la erradicación de la impunidad. Por lo tanto, su acción es complementaria a los sistemas penales de los Estados Parte en cuanto a la

11 CORTE CONSTITUCIONAL. Sentencia N ${ }^{\circ}$ C-578, julio 30 de 2002. 
sanción de los criminales, la reparación a las víctimas y el restablecimiento de los derechos.

La Corte Penal Internacional es autónoma e independiente de la ONU en la toma de decisiones. Su financiación se configuró de tres posibles maneras, así: por cuotas de los Estados adherentes; por fondos de las Naciones Unidas, previa aprobación de la Asamblea General; y por aportes voluntarios.

\section{ESTRUCTURA DEL ESTATUTO DE ROMA DE LA CORTE PENAL INTERNACIONAL}

El Estatuto de Roma se estructura sobre un Preámbulo y trece partes, constitutivas de 128 Artículos. Es un texto bien argumentado de fácil comprensión con versatilidad en su desenvolvimiento. El contenido del texto y la conexidad coherente entre sus partes, lo constituyen como el mejor instrumento jurídico escrito de Derecho Internacional Público.

\section{PREÁMBULO}

En el preámbulo, los Estados que adoptan el Estatuto de Roma expresan con claridad su decisión de mancomunar las voluntades políticas con el objetivo de iniciar un nuevo momento de las relaciones internacionales, en el cual la impunidad de crímenes contra la humanidad no siga siendo la constante.

Se advierte allí, que los lazos que aún unen las diversas culturas del mundo están a punto de entrar en ruptura y por lo tanto la creación de la Corte Penal Internacional con un carácter permanente, imparcial e independiente es una necesidad imperiosa, lo cual concuerda con la salvaguarda de los intereses de las generaciones presentes y futuras.

Configura, que será con base en la cooperación internacional decidida, continuada y abierta como se podrán ir logrando los objetivos que se traza la Corte Penal Internacional, cuya acción será complementaria de los sistemas penales de los Estados Partes que se adhieran.

Primera Parte: Del establecimiento de la Corte. Artículos 1 al 4

Declara la creación oficial de la Corte, definiendo su naturaleza, sus atribuciones jurídicas, su relación con las Naciones Unidas y su sede.

Segunda Parte: De la competencia, la admisibilidad y el derecho aplicable. Artículos 5 al 21

Define la competencia, la admisibilidad y la posible acción de la Corte. Tipifica cuatro crímenes y sus componentes fundamentales, sobre los cuales la Corte tendrá competencia. Regula los mecanismos de remisión de los asuntos por parte de los Estados, así como los casos controversiales respecto a impugnaciones, reconocimiento de cosa juzgada y el derecho aplicable por parte de la Corte.

Tercera Parte: De los principios generales de derecho penal. Artículos 22 al 33

Sustenta los principios generales del derecho penal que guiarán la aplicación de justicia por parte de la Corte, identificando los siguientes:

1. Nullum crimen sine lege.

2. Nulla pena sine lege.

3. La irretroactividad ratione personae.

4. La responsabilidad penal individual.

5. La Corte no tendrá competencia sobre menores de 18 años.

6. La igualdad en la aplicación del Estatuto.

7. La responsabilidad de los jefes y otros superiores en los crímenes. 
8. La imprescriptibilidad de los crímenes.

9. La intencionalidad.

10. Las circunstancias eximentes de responsabilidad penal.

11. Las consecuencias de error de hecho o de derecho.

12. Las implicaciones de llevar a cabo órdenes superiores en el acometimiento de crímenes.

13. Las disposiciones jurídicas en la determinación de responsabilidad penal del acusado.

Cuarta Parte: De la composición y administración de la Corte. Artículos 34 al 52

Identifica los órganos de la Corte, sus competencias, sus funciones, sus procedimientos, su funcionamiento y sus relaciones. Asimismo, define las características cualitativas de los miembros de estos órganos, sus privilegios, inmunidades y los mecanismos de regulación y control entre éstos. Define los aspectos disciplinarios y todo lo relacionado con la parte administrativa.

Quinta Parte: De la investigación y el enjuiciamiento. Artículos 53 al 61

Determina todo el proceso, desde el inicio de la investigación, pasando por las disposiciones de la detención del acusado, hasta las primeras diligencias de la Corte en las cuales se exige la confirmación de los cargos antes de iniciar el juicio. Detalla las funciones y competencias tanto del Fiscal como de la Sala de Cuestiones Preliminares.

Sexta Parte: Del juicio. Artículos 62 al 76

Trata sobre las funciones y competencias de la Sala de Primera Instancia en el desarrollo del juicio al acusado. Plantea como requisito, la pre- sencia de éste en el juicio, dando especial énfasis a sus derechos.

Ubica todo lo relacionado con la protección de las víctimas y testigos y las reglas referidas a la práctica de pruebas. Define prerrogativas para garantizar el manejo de la información de implicados y de terceros que pudieran atentar contra la seguridad nacional de los Estados.

Identifica los requisitos para proferir el fallo condenatorio y sus características, así como la reparación a las víctimas.

Así mismo, alude a los posibles delitos de administración de justicia y las sanciones por falta de conducta decorosa en la Corte.

Séptima Parte: De las penas. Artículos 77 al 80

Especifica la imposición de las penas y su aplicabilidad y cumplimiento de los Estados Partes.

Octava Parte: De la apelación y la revisión. Artículos 81 al 85

Define los mecanismos e instrumentos para llevar a cabo la apelación y la revisión de un fallo absolutorio o condenatorio. Plantea los casos de eventual indemnización del detenido o condenado cuando éste haya sido perjudicado.

Novena Parte: De la cooperación internacional y la asistencia judicial. Artículos 86 al 102

Aborda la obligación general de cooperación de Ios Estados Partes con la Corte. Trata tres aspectos. El primero referido a la entrega de criminales a la Corte y la solución de dificultades que se puedan presentar para llevar a cabo tal remisión. El segundo alude a otras formas de cooperación como las solicitudes de asistencia y sus formas operativas. El tercero trata sobre disposiciones específicas para posibilitar material y jurídicamente la solicitud y entrega de personas a la Corte. 
También trata sobre el principio de la especialidad en la materia, el cual implica que la persona remitida a la Corte no puede ser condenada por un delito anterior a su entrega, siempre y cuando éste no sea la causa por la cual se le procesa.

Décima Parte: De la ejecución de la pena. Artículos 103 al 111

Identifica la función de los Estados en la ejecución de la pena, las posibilidades de reducción de las mismas y las medidas que se habrán de tomar en caso de evasión del condenado.

Décima Primera Parte: De la Asamblea de los Estados Partes. Artículo 112

Trata todo lo referente a las atribuciones y funcionamiento de la Asamblea de los Estados Partes. Precisa sobre sus órganos, los procedimientos, mecanismos e instrumentos de regulación y decisión, así como los idiomas oficiales de trabajo en las sesiones.

Décima Segunda Parte: De la financiación. Artículos 113 al 118

Esboza todo lo relacionado con las formas de financiación de la Corte y los instrumentos contables, así como los mecanismos de control.

Décima Tercera Parte: Cláusulas finales. Artículos 119 al 128

Define con claridad soluciones de posibles controversias que pudieran surgir de la acción judicial de la Corte. Alude específicamente a lo relacionado con:

1. La prohibición de presentar reservas al Estatuto; 2 . Al régimen de enmiendas; 3 . A la revisión del Estatuto; 4. A las disposiciones de transición y la firma, certificación, aceptación, aprobación o adhesión al Estatuto; 5. La entrada en vigor del Estatuto.

\section{LAS DEFINICIONES DE MAYOR TRASCENDEN- CIA EN EL ESTATUTO DE ROMA ${ }^{12}$}

El aspecto de mayor controversia, antes de adoptarse el Estatuto, lo constituyó el carácter independiente, imparcial y eficaz de la Corte Penal Internacional. Esto se debatió durante tres años, siendo su síntesis las definiciones tomadas en la adopción del Estatuto en julio de 1998.

Por ello, el tratamiento de los temas que soportarían epistemológica y jurídicamente la independencia de la Corte se focalizaron en siete puntos, así:

1. Un régimen de competencia libre de cualquier requisito de consentimiento por parte de los Estados.

2. Independencia del Consejo de Seguridad.

3. La competencia del Fiscal, la cual le daría la capacidad para iniciar investigaciones "ex oficio".

4. Aplicación del principio de la complementariedad, o la prioridad de investigaciones y juzgamientos legítimos a nivel interno de los Estados.

5. Competencia sobre los crímenes de guerra independientemente de que hayan sido cometidos en conflictos internacionales o internos.

6. La obligación de los Estados Partes de cumplir con las peticiones de cooperación de la Corte. 
7. Los criterios más altos de la justicia internacional respetando los derechos del acusado y la protección adecuada de los testigos.

Teniendo como parámetros medulares estos siete aspectos, el balance arrojado por la redacción y disposiciones del texto final del Estatuto de Roma es altamente positivo para la cualificación del Derecho Internacional Público.

El cuerpo conceptual y jurídico del Estatuto de Roma garantiza el funcionamiento, la eficacia, el respaldo real de los Estados Partes y la duración consistente de la Corte. Con ello, se da un paso importante en la consolidación de los Estados Sociales de Derecho en el mundo, el fortalecimiento de las legislaciones internas de los países en aras de la protección de los derechos humanos y la lucha contra la impunidad.

\section{LA CORTE PENAL INTERNACIONAL EN RELACIÓN CON COLOMBIA ${ }^{13}$}

A nivel interno, en Colombia, se llevó a cabo el correspondiente proceso de análisis, cogestión y coordinación entre los órganos del poder público, lo cual garantizó que se argumentara adecuadamente la aprobación del Estatuto de Roma de la Corte Penal Internacional, sin vicios de forma.

La sanción presidencial se dio a través de la ley 742 del 5 de junio de 2002, siendo declarado exequible por la Corte Constitucional a través de la Sentencia C-578 de julio 30 de 2002. El gobierno colombiano lo ratificó ante el Secretario General de la Organización de las Nacionales Unidas el 5 de agosto de 2002.

En Colombia y en la comunidad internacional hubo manifestaciones de fuerte controversia por la declaración del gobierno colombiano respecto a hacer uso de la disposición de transición planteada en el Artículo 124 del Estatuto, la cual dispone la facultad de los Estados de excluir la competencia de la Corte Penal Internacional sobre crímenes de guerra cometidos en su territorio o por sus ciudadanos durante un período de 7 años.

Las ONGs internacionales y nacionales de derechos humanos expresaron su desacuerdo calificando esta determinación gubernamental como una burla del Estado colombiano.

La apreciación contraria en Colombia, expresó enfáticamente que la creación de la Corte Penal Internacional podría ser manipulada indebidamente para convertirla en una herramienta jurídica contra las autoridades en su lucha contra el terrorismo internacional. Por ello, el recurso de hacer válido el artículo transitorio se califica como una determinación responsable, prudente y respetuosa del Derecho Internacional Público y del Estatuto de Roma.

\section{TRASCENDENCIA ESTRATÉGICA DE LA CORTE PENAL INTERNACIONAL}

La creación de la Corte Penal Internacional, con su carácter permanente, autónomo y universal, representa la síntesis de los variados intentos de la comunidad internacional de erigir un mecanismo de aplicación de justicia y contra la impunidad de crímenes cometidos contra la integridad de la humanidad y en detrimento continuado de la paz mundial. 13 AUTORES VARIOS. La Corte Penal Internacional. Estudiantes de cuarto semestre de Relaciones Internacionales. Universidad Militar Nueva
Granada, 2003, Bogotá. 
La creación de la Corte Penal Internacional significa el resultado del trabajo mancomundado de la comunidad de naciones y de su consenso respecto a que su acción y cobertura deberá garantizar la protección integral de los derechos humanos, desde el núcleo del derecho consuetudinario mínimo hasta la preservación de la paz orbital, juzgando y castigando individualmente todo tipo de crímenes contra la humanidad violatorios del Derecho Internacional Humanitario.

El carácter integral e independiente de la Corte Penal Internacional avisora en su intencionalidad política que la aplicación de justicia no se hará como en el pasado, en donde la conformación de tribunales y sus respectivos códigos representaban intereses específicos de hegemonías internacionales, relaciones de poder predeterminadas y negociaciones de roles individualistas que representaron inmunidades perversas, arrojando el cuadro de impunidad más atroz jamás presentado.

No ha sido menos atroz el tejido de impunidad internacional que los mismos crímenes cometidos contra los pueblos del mundo. La conformación de la Corte advierte a todo tipo de políticas criminales y de organizaciones violatorias del Derecho Internacional Humanitario, que no quedarán exentas de ser castigadas a través del procesamiento y juzgamiento de sus principales detentores $y$ ejecutores.

Es sabido que todos los intentos anteriores estuvieron matizados por conflictos de intereses entre las potencias mundiales. En todos los casos que antecedieron la creación de la actual Corte, los mecanismos e instrumentos habilitados se dieron dentro del concierto de crímenes incursos que fueron juzgados por las potencias victoriosas después de cada conflicto bélico.

Estos instrumentos no tuvieron nunca el juzgamiento de responsabilidades recíprocas en la violación de los derechos humanos y del derecho internacional humanitario en aquellos conflictos. Es decir, al no existir un Estatuto Integral, ni un instrumento habilitado con competencia plena, permanente e independiente, se juzgó unilateralmente a los responsables de crímenes cometidos por los que perdieron las guerras.

No se sabe qué pasó con el análisis sobre las atrocidades cometidas contra la población civil por parte de los ejércitos victoriosos y por consiguiente, sobre el establecimiento de responsabilidades individuales de sus dirigentes.

Las características de la Corte Penal Internacional anuncian una lucha efectiva y frontal contra la impunidad de crímenes internacionales, los cuales hasta hoy día han ofendido y lacerado profundamente la conciencia y dignidad humana, poniendo en tela de juicio la razón de ser de la humanidad frente a sí misma y frente al ámbito del tiempo sagrado de las divinidades.

La creación de la Corte Penal Internacional expresa el significativo avance del Derecho Internacional, producto, desde luego, del aporte de las diferentes doctrinas jurídicas del mundo y de su disposición a la sensibilización, flexibilización y adecuación para el consenso, en procura de la protección y preservación del decoro y la dignidad humana.

\section{BIBLIOGRAFÍA}

CONSTITUCIÓN POLÍTICA DE COLOMBIA. Versión actualizada. 2002.

CORTE CONSTITUCIONAL. Sentencia N ${ }^{\circ} \mathrm{C}-578$, julio 30 de 2002.

HUMAN RIGHTS WATCH. Justice in the Balance. 
Recommendations for and Effective and Independent ICC. Julio 1998.

MENDOZA, Álvaro. Teoría y sinopsis de la Constitución de 1991. Segunda edición, 1996.

MENDOZA, Álvaro. La Corte Penal Internacional y la impunidad. Universidad Militar Nueva Granada. Bogotá, noviembre de 2001.

PETER, Maina Chris. Cruz Roja Internacional. Revista Nº 144.

PIGRAU SOLE, Antoni. Revista Naciones Unidas. Junio de 1998.

SUHR, Brigitte y DUFFY, Helen. El debate sobre Compatibilidad Constitucional con la Corte Penal Internacional. Human Rights Watch. 2000.

UNIVERSIDAD MILITAR NUEVA GRANADA. Geoestrategia y relaciones internacionales. Volumen 2. 2002.

UNIVERSIDAD EXTERNADO DE COLOMBIA. El Estatuto de Roma de la Corte Penal Internacional. 1999.

AA.W. La Corte Penal Internacional. Estudiantes de cuarto semestre de Relaciones Internacionales. Universidad Militar Nueva Granada. 2003, Bogotá. 